\title{
Cutaneous Tuberculosis: Clinicopathologic Arrays and Diagnostic Challenges
}

\author{
Priyatam Khadka $\mathbb{D}^{\mathrm{D}},{ }^{1,2}$ Soniya Koirala, ${ }^{3,4}$ and Januka Thapaliya ${ }^{2}$ \\ ${ }^{1}$ Department of Microbiology, Tribhuvan University Teaching Hospital, Kathmandu, Nepal \\ ${ }^{2}$ M.Sc. Medical Microbiology, Tri-Chandra Multiple Campus, Tribhuvan University, Nepal \\ ${ }^{3}$ Department of Dermatology and Venerology, Tribhuvan University Teaching Hospital, Kathmandu, Nepal \\ ${ }^{4}$ M.D. Dermatology, Maharajgunj Medical Campus, Tribhuvan University, Nepal
}

Correspondence should be addressed to Priyatam Khadka; khadka.priyatam@gmail.com

Received 7 April 2018; Accepted 25 June 2018; Published 9 July 2018

Academic Editor: Luigi Naldi

Copyright (C) 2018 Priyatam Khadka et al. This is an open access article distributed under the Creative Commons Attribution License, which permits unrestricted use, distribution, and reproduction in any medium, provided the original work is properly cited.

The clinicopathological manifestations of cutaneous tuberculosis are diverse. The precise diagnosis is often overlooked, due to clinical presentations as those of cutaneous diseases with different etiology and the relative paucity of the pathogens in the lesions. Meanwhile, almost all of the diagnostic methods confer lower sensitivity and specificities which augments further diagnostic challenges. This article revises the current scenario of the disease's physiopathology and underscores clinicopathological challenges, due to multifaceted presentations of cutaneous tuberculosis, in the diagnosis.

\section{Background}

Cutaneous tuberculosis is a relatively uncommon, comprising $1-1.5 \%$ of all extrapulmonary tuberculosis manifestations, which manifests only in $8.4-13.7 \%$ of all tuberculosis cases [1]. Although rare, given its global prevalence, it is imperative for the clinicians to distinguish the many clinical variants of cutaneous tuberculosis and the masquerading infections-granulomatous syphilis, discoid lupus erythematosus, psoriasis, tuberculoid leprosy, sarcoidosis, actinomycosis, mycetoma, bacterial abscesses, and other skin infections-to preclude missed or delayed diagnosis [2, 3]. Most of the diagnostic methods for cutaneous tuberculosis confer lower sensitivity and specificities. Therefore, the physicians must resort to every possible test along with broad clinical consideration; hence the summation of positive rudiments would be auxiliary in precise diagnosis.

\section{Epidemiology}

Tuberculosis represents a major public health problem in Southeast Asia, since a larger proportion (45\%) of total estimated 10.4 million infective cases were listed in the region [4]. Compiling the toll death rate, Southeast Region and African Regions accounted for $85 \%$ of total death due to tuberculosis [4]. TB ranks the 6th leading cause of death in Nepal [5]. The prevalence study was not done in Nepal due to impassiveness of government participation in the health sector; however, annually, 34,122 cases of tuberculosis were reported to NTP [6].

Tuberculosis is endemic in Nepal; limited cases of cutaneous tuberculosis were reported, however. The incidence of cutaneous tuberculosis in Central Nepal was reported as $0.1 \%$; nonetheless, the exact incidence is still anonymous over the country. The clinicoepidemiological study done in Nepal by Dwari et al. 2010 revealed tuberculosis verrucous (48\%) as predominant clinical type [7]; however, on referencing to earlier studies, Lupus vulgaris was the most common (64\%), followed by tuberculosis verrucosa cutis (19\%) and papulonecrotic tuberculid (4\%) [8]. Ironically, cases of cutaneous multidrug resistant tuberculosis (MDR-TB) - resistant with at least two of the most potent first-line anti-TB medications, isoniazid and rifampicin-and XDR-TB-MDR strains that are resistant to fluoroquinolones plus one of the injectables 
such as kanamycin, amikacin, and capreomycin-have also been reported from India and China abutting Nepal [9-11]. Nevertheless, the exact epidemiological entity of perchance MDR/XDR cutaneous tuberculosis cases is still unbeknownst or unreported from Nepal.

\section{Etiological Agent}

The main etiological agent of the Cutaneous tuberculosis is Mycobacterium tuberculosis-occasionally $M$. bovis or BCG vaccine (an attenuated strain of $M$. bovis) $[12,13]$.

Mycobacterium tuberculosis is a straight or slightly bent (rod-shaped), nonmotile, nonsporulated, bacillus, being 1 to $10 \mu \mathrm{m}$ long and 0.2 to $0.6 \mu \mathrm{m}$ wide; its most important feature is acid-fastness due to high lipid content in the cell wall. Approximately there are 4000 genes with most of them involved in the mechanism of immune system invasion and 200 of them for lipid metabolism; consequently, the pathogen is able to survive both inside and outside the phagocytic cells [14]. Meanwhile, as lipids are the main energy source of Mycobacterium tuberculosis, the pathogen is directly responsible for multiplying in host tissue and forming cellular walls $[14,15]$.

\section{Route of Infection}

Cutaneous tuberculosis can be acquired from hematogenous or lymphatic dissemination of a pulmonary focus or by direct inoculation. The pivotal factor for the clinical presentations prior to contact with bacilli is the host natural immune response, however.

Exogenous infection occurs with direct inoculation of bacilli into the skin of predisposed individuals (tuberculous chancre, tuberculosis verrucosa cutis) [1]

Endogenous infection is secondary to a preexisting primary focus and may result from contiguous (orificial tuberculosis, scrofuloderma), hematogenous (acute miliary tuberculosis, tuberculous gumma, and lupus vulgaris), or lymphatic dissemination (lupus vulgaris) $[2,16]$.

\section{Classifications of Cutaneous Tuberculosis Based on a Load of Pathogens}

Based on a load of the pathogens on skin, the tuberculosis variant can be classified into two broad categories.

Multibacillary forms (easily detected in cutaneous tissue) include tuberculous chancre, scrofuloderma, orificial tuberculosis, acute miliary tuberculosis, and tuberculous gumma $[17,18]$.

Paucibacillary forms (bacilli being sparse) include TB verrucosa cutis, tuberculoid, and lupus vulgaris [17, 18].

\section{Clinical Manifestations of Cutaneous Tuberculosis}

Cutaneous tuberculosis exhibits diverse clinical manifestations: inflammatory papules, verrucous plaques, suppurative nodules, chronic ulcers, and other atypical lesions [19].

\section{Exogenous Cutaneous Tuberculosis}

7.1. Tuberculosis Chancre. The direct inoculations of Mtb in the skin from the traumatic injuries or surgical procedures performed with unsterilized materials and even after tattoos or body piercing lead to acquired tuberculosis chancre. Progressing from a firm, painless, reddish-brown, slow-growing papule, or nodule, after 2 to 4 weeks it develops into the friable ulcers - tendency to bleed with a granular surface [20]. Furthermore, the bacilli disseminate to regional lymph nodes via lymph.

Presumptive identification can be done with histopathological examinations, where the acute neutrophilic inflammatory reaction prolific in AFB and necrotic areas are usually noticed [16]. Sequentially, the lesion acquires a granulomatous form with enlarged giant cells after 3 to 6 weeks with the reduced number of bacilli [20].

7.2. Tuberculosis Verrucosa Cutis. Tuberculosis verrucosa cutis, the usual exogenous form of tuberculosis, is more common in an anatomist, physicians, and bare-footed children of tropical zones, since the infection proceeds with an injured dermal layer [1]. The lesions-solitary, painless, and without adenopathy-are more seen commonly in the extremities prone to traumas [16]. The lesions jerk as erythematous papules to verrucous plaques with peripheral extension.

\section{Endogenous Tuberculosis}

8.1. Scrofuloderma. Scrofuloderma, also called colliquative cutis, is a common form of cutaneous tuberculosis; it results from direct extension from an underlying tuberculosis lesion in lymph node, bone, joints, or testicles $[1,2]$. The neck, axillae, and groin are often involved, with the cervical lymph nodes as a common source of infection [1]. Early lesions appear as firm, painless, subcutaneous, and red-brown nodules which advanced to ulcers and discharging sinus [21]. Spontaneous healing may occur, leaving keloid scars, retractions, and the atrophic sequel [21].

8.2. Orificial Tuberculosis. Orificial tuberculosis-a very rare form of cutaneous tuberculosis - is clinically characterized by ulcerations at mucocutaneous orifices including mouth, nose, perianal region, and genitalia and adjacent skin, usually advanced form of lungs, intestinal, or genitourinary tuberculosis [22]. The lesions, about 1 to $3 \mathrm{~cm}$ in diameter, appear as friable, painful erythematous-to-yellowish papules and nodules, which may advance to painful ulcers [16]. Edema and inflammation are obvious in perilesional tissue.

8.3. Lupus Vulgaris. Lupus vulgaris is the most common form of cutaneous tuberculosis in Europe, India, and Nepal $[8,13$, 16]. It is a chronic, progressive, paucibacillary form of cutaneous tuberculosis which occurs primarily in the previously sensitized individual $[23,24]$. The infection occurs endogenously via lymphohematogenous route and occasionally via exogenous route-with drainage scar of scrofuloderma [25].

The most typical clinical feature of lupus vulgaris is a papulotubercular lesions commonly on the legs and buttocks, 
which eventually coalesce into a plaque (Figures 1, 2(a), and 2(b)) [12]. The plaques grow peripherally, with serpiginous or verrucous borders, accompanied by central discoloration and atrophy [25]. Besides, the classic appearance is described as "apple jelly nodules" observed on diascopy $[24,26]$.

8.4. Tuberculous Gumma. Tuberculous gumma, also known as metastatic tuberculosis abscess, is an outcome of hematogenous dissemination of mycobacteria from primary focus especially in an immunocompromised host, scarcely in an immunocompetent host too $[17,27]$. Clinically it may bear a semblance to scrofuloderma; few lesions affecting trunks and extremities with inconsistent subcutaneous nodules having tendency to ulcerate and drain caseous secretion are seen in tuberculous gumma [23].

8.5. Acute Miliary Tuberculosis. It is a rare presentation of cutaneous tuberculosis predominantly in severely immunocompromised host, demonstrating anergy. The bulk of cases have been increasing primarily due to coinfection with HIV with declining CD4 count below 100 cells/ $\mu \mathrm{L}$ [28]. Clinically, diverse cutaneous lesions-erythema and erythematouswhitish or erythematous-purplish papules-may be noticed which later on break to form umbilication and crust formation leaving hypochromic scars [17].

\section{Tuberculids}

Tuberculids are acute or chronic cutaneous forms of tuberculosis, appearing with diverse clinical forms, having a propensity of hyperergic expressions, active $\mathrm{TB}$, or disseminated forms [20]. The discrete relationship between tuberculids and $\mathrm{TB}$ continues to be debated because the clinical forms usually have a symmetrical distribution, tuberculous involvement (usually inactive) of viscera or lymph nodes, and the absence of AFB (low positivity to culture and PCR) in the lesions $[16,26]$.

9.1. Papulonecrotic Tuberculids. Papulonecrotic tuberculids are the commonly observed form of cutaneous in children and young people [29]. They appear as painless, symmetrical erythematous, or violaceous papulonodular lesions noted particularly around the face, ears, extensor areas of the trunk, extremities, and buttocks, leaving a depressed scar [26].

9.2. Lichen Scrofulosorum. Lichen scrofulosorum is an eruption of multiple, small, grouped, asymptomatic, firm, perifollicular, lichenoid papules or plaques often affecting children and adults with underlying diseases of bone and lymph nodes $[16,26]$. The dermatosis leaves no scar after months or years. The onset of this tuberculid was speculated, after BCG vaccinations and in the patient infected with $M$. aviumintracellulare [30].

9.3. Erythema Induratum of Bazin. Erythema induratum of Bazin is a granulomatous lobular panniculitis, which appears as erythematous-purplish subcutaneous nodules usually in legs and thighs [26]. The nodules advance few centimeters in diameter forming deep ulcers with caseous discharges and leave pigmented scar without or after successful treatment.

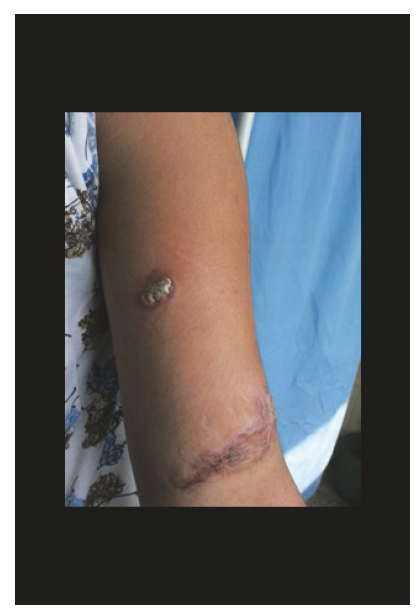

FIGURE 1: Erythematous plaque $(2 * 1 \mathrm{~cm})$ of lupus vulgaris on right forearm of a 17-year-old female with a history of trauma forming a linear scar $(4 * 2 \mathrm{~cm})$, visiting TUTH.

The relapse, however, may occur in flares every 3-4 months with similar clinical presentations [1]. Besides, the tendency of coinfectivity with systemic diseases like sarcoidosis is the differential clinical diagnosis of erythema nodosum $[16,21]$.

\section{Diagnosis of Cutaneous Tuberculosis}

10.1. Differential Diagnosis. The precise diagnosis is often significantly deferred and delayed, as cutaneous TB is not routinely considered in the differential diagnosis due to the relative paucity of pathogens in lesions and varied clinical manifestations (Table 1) [2, 16, 19, 31-33]. Hence, differential diagnosis is obligatory for the successful clinical management and treatment.

\subsection{Laboratory Diagnosis}

10.2.1. Tuberculin Skin Test. This technique involves an injection of $0.1 \mathrm{ml}$ tuberculin, purified protein derivatives (PPD) derived from the attenuated strain of M. tuberculosis, intradermally, and read after 48 to 72 hours; on positive interpretation, the induration diameter exceeds the measuring of $10 \mathrm{~mm}$. The reaction is the classic example of delayed hypersensitivity reaction, where sensitized T-cells by prior infection are recruited thereby releasing the lymphokine [34]. These lymphokines induce indurations through local vasodilation, edema, fibrin deposition, and recruitment of other inflammatory cells to the area $[34,35]$. TST has the sensitivity between $33 \%$ and $96 \%$ and specificity of $62.5 \%$ with cutoff $10 \mathrm{~mm}$ for cutaneous tuberculosis; the sensitivity, however, exceeds $97 \%$ in an unvaccinated population $[36,37]$.

Furthermore, on analyzing clinical forms of cutaneous tuberculosis separately, positivity, intensity of the tuberculin skin test also diverges (Table 2). Conclusively, neither a positive TST necessarily indicates active infection nor a negative TST rules out the infection persistence.

10.2.2. Immunological Tests (Interferon Gamma-Release-Assay). The FDA approved immunological tests, QuantiFERON and 
TABLE 1: Clinical manifestations of cutaneous tuberculosis and its differential diagnosis.

\begin{tabular}{|c|c|c|c|}
\hline S. N & $\begin{array}{r}\text { Classi } \\
\text { tub }\end{array}$ & & Diagnostic considerations \\
\hline \multirow[b]{2}{*}{1} & \multirow[b]{2}{*}{$\begin{array}{l}\text { Exogenous } \\
\text { cutaneous } \\
\text { Tuberculosis }\end{array}$} & $\begin{array}{c}\text { Tuberculosis } \\
\text { chancre }\end{array}$ & $\begin{array}{c}\text { sporotrichosis, leishmaniasis, atypical } \\
\text { mycobacteriosis, syphilis, cat scratch } \\
\text { disease and tularemia }\end{array}$ \\
\hline & & $\begin{array}{c}\text { Tuberculosis } \\
\text { verrucosa cutis }\end{array}$ & $\begin{array}{l}\text { paracoccidioidomycosis, leishmaniasis, } \\
\text { sporotrichosis, tuberculosis verrucosa } \\
\text { and chromomycosis. Lobomycosis, } \\
\text { atypical mycobacteriosis, hypertrophic } \\
\text { lichen planus, verrucous carcinoma, } \\
\text { iododerma, bromoderma, verruca } \\
\text { vulgaris, keratoacanthoma centrifugum } \\
\text { and pyoderma vegetans }\end{array}$ \\
\hline \multirow{5}{*}{2} & \multirow{5}{*}{$\begin{array}{l}\text { Endogenous } \\
\text { cutaneous } \\
\text { tuberculosis }\end{array}$} & Scrofuloderma & $\begin{array}{l}\text { tertiary syphilis, paracoccidioidomycosis, } \\
\text { actinomycoses, lymphogranuloma } \\
\text { venereum, bacterial abscesses, tumor } \\
\text { metastasis, histiocytosis and hidradenitis }\end{array}$ \\
\hline & & $\begin{array}{c}\text { Orificial } \\
\text { tuberculosis }\end{array}$ & $\begin{array}{c}\text { bullous diseases, trauma, fungal diseases, } \\
\text { syphilis, sarcoidosis, or squamous cell } \\
\text { carcinoma }\end{array}$ \\
\hline & & Lupus vulgaris & $\begin{array}{c}\text { basal cell carcinoma, sarcoidosis, discoid } \\
\text { lupus erythematosus, Leprosy, Deep } \\
\text { Fungal infections }\end{array}$ \\
\hline & & $\begin{array}{l}\text { Tuberculous } \\
\text { gumma }\end{array}$ & $\begin{array}{l}\text { leishmania, sporotrichosis, nocardiosis, } \\
\text { atypical mycobacteria (Mycobacterium } \\
\text { marinum), pyogenic infections } \\
\text { (Staphylococcus aureus, Streptococcus), } \\
\text { and deep fungal infections }\end{array}$ \\
\hline & & $\begin{array}{l}\text { Acute miliary } \\
\text { tuberculosis }\end{array}$ & metastatic carcinomas \\
\hline \multirow{3}{*}{3} & \multirow{3}{*}{ Tuberculids } & $\begin{array}{l}\text { Papulonecrotic } \\
\text { tuberculid }\end{array}$ & $\begin{array}{l}\text { pityriasis lichenoides et varioliformis acuta } \\
\text { (PLEVA), leukocytoclastic necrotizing } \\
\text { vasculitis, pruritus and secondary syphilis }\end{array}$ \\
\hline & & $\begin{array}{l}\text { Lichen } \\
\text { scrofulosorum }\end{array}$ & $\begin{array}{l}\text { lichen planus and lichen nitidus, syphilid } \\
\text { lichenoides, eczematid, keratosis pilaris, } \\
\text { pityriasis rubra pilaris (PRP) and } \\
\text { micropapular sarcoidosis }\end{array}$ \\
\hline & & $\begin{array}{l}\text { Erythema } \\
\text { induratum of Bazin }\end{array}$ & $\begin{array}{l}\text { erythema nodosum, cutaneous } \\
\text { polyarteritis, pancreatic panniculitis, } \\
\text { lupus profundus, subcutaneous } \\
\text { sarcoidosis and cutaneous T-cell } \\
\text { lymphoma }\end{array}$ \\
\hline
\end{tabular}

TABLE 2: TST result in different forms of cutaneous tuberculosis.

\begin{tabular}{ll}
\hline Clinical forms of cutaneous tuberculosis & Tuberculin skin test result \\
\hline Tuberculosis chancre & initially negative, but becomes positive during course of disease (usually after 15 days) \\
Tuberculosis verrucosa & strongly positive \\
Lupus vulgaris & usually positive \\
Scrofuloderma & strongly positive \\
Orificial tuberculosis & negative \\
Acute cutaneous miliary tuberculosis & negative \\
Papulonecrotic tuberculoid & positive \\
Lichen scrofulosorum & positive \\
Erythema induratum of Bazin & positive \\
\hline
\end{tabular}




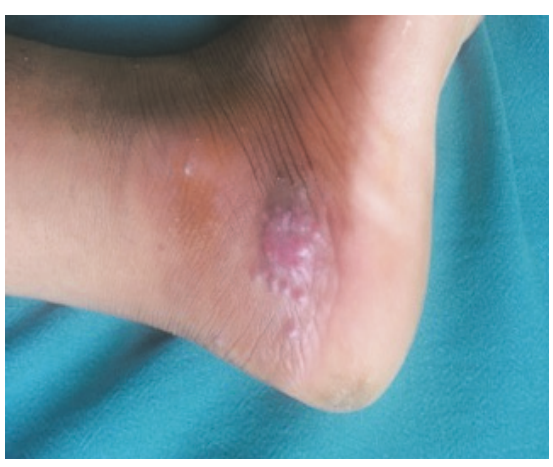

(a)

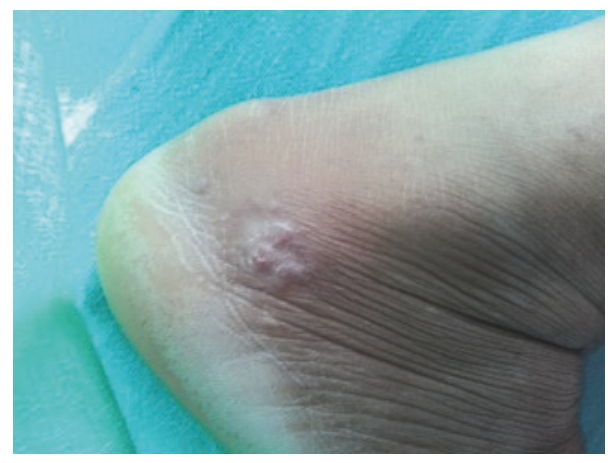

(b)

Figure 2: (a) Multiple erythematous papules of lupus vulgaris below lateral malleolus of right foot of 34-year-old female with a history of trauma on the right foot working in field 6 months earlier (before treatment). (b) The erythematous plaque reduced but did not resolve completely after antitubercular therapy; antitubercular therapy continued for three more months.

EliSpot, assess sensitizations to M. tuberculosis by measuring the amount of INF gamma released by lymphocytes confronted with $M$. tuberculosis specific antigens [16]. The sensitivity and specificity of QuantiFERON are $89 \%$ and $99 \%$, respectively, while EliSpot has the sensitivity of $98.8 \%$ and a specificity of $100 \%$ [38]. Unlike tuberculin skin test (TST), it detects disease in patients who have been vaccinated against BCG (latent infection) - and active infection too.

These tests are still not in routine-practice in our midst, because of high cost and laborious cell extract procedure from culture to antigen preparation (particularly in EliSpot).

10.2.3. Histopathology. Histopathology of a skin biopsy shows granulomatous presentations as those of cutaneous diseases with different etiology — cutaneous leishmaniasis, tuberculid leprosy, superficial granulomatous pyoderma, cutaneous sarcoidosis, lupus miliaris disseminatus faciei, and chromomycosis $[16,19,33]$. Meanwhile, the exact elucidation in diagnosis of cutaneous tuberculosis could not be done; however, the characteristic feature (well-formed granulomas with absence of caseous necrosis, granulomas with caseous necrosis, and the presence of poorly formed granulomas with intense caseous necrosis) would be auxiliary to differentiate types of cutaneous tuberculosis (Table 3 ) $[16,19,21,26,28$, $33,39]$.

The equivocal manifestation of cutaneous tuberculosis to correlate the histologic with clinical observations in an evidence-based diagnosis is imperfect and lacking pragmatics.

10.2.4. Diagnosis by Test: Staining and Culture. The mycobacterial cell wall is rich in complex lipids which resists the acid and alcohol; hence the pathogen is termed as acid-fast bacilli (AFB). Staining techniques include Ziehl-Neelsen (common in practice), Kinyoun, and fluorochrome-based techniques with auramine-rhodamine. Microscopic observation of AFB in staining of tissue or secretions enables the empiric therapy if there are sufficient clinical suspicions. However, this does not necessarily suggest the cutaneous tuberculosis, since the other pathogens like Nocardia, Corynebacterium, nontuberculous mycobacteria, and even artifacts may reveal acid-fast characteristics $[38,40]$.

Furthermore, the lower sensitivities of staining results in extrapulmonary compared to pulmonary tuberculosis limit the applicability of the test $[16,37,38]$. The cultures of the pathogen, Mycobacterium tuberculosis, on specific solid media or by automatic detection of its metabolites in liquid media remain the gold standard method, for identifications and their drug sensitivities. However, the long generation time of the pathogens to grow and lower sensitivity of culture results for lesions and tissue samples attribute further challenges in prompt and accurate diagnosis of cutaneous tuberculosis $[16,38]$.

10.2.5. Amplifications of Nucleic Acids (PCR). The detection of Mycobacterium genus using bacterial 16S ribosomal DNA with PCR assays is now termed as a milestone in a diagnosis of pulmonary tuberculosis and several forms of cutaneous tuberculosis. DNA present in a sample of fresh tissues, blood, or a paraffin block even formalin fixed paraffin embedded sections, is amplified and it can then be identified, confirming the presence of mycobacteria $[16,33,41]$.

PCR assay has augmented sensitivity and specificity in the diagnosis of cutaneous tuberculosis (Table 4) [42-55]; nevertheless, like other diagnostic approaches it is inconclusive in paucibacillary forms due to unevenly microbial distributions $[25,45]$.

10.2.6. Genotyping. Genotyping, the recent advance in the diagnosis of cutaneous tuberculosis, has a tendency to separate atypical mycobacteria from $\mathrm{Mtb}$ - and detect mutant if it persists inducing drug resistance in the pathogen. The major molecular typing methods-Spoligotyping, MIRU-VNTR (Mycobacterial Interspersed Repetitive Unit-Variable Number Tandem Repeats), and RFLP-detect Mycobacterium tuberculosis, DNA, or RNA in clinical specimens by in vitro nucleic acid amplifications, empowering investigations into epidemiology, transmission, and PTB outbreaks [56]. The 
TABLE 3: Histopathological features of cutaneous tuberculosis.

\begin{tabular}{|c|c|c|}
\hline $\begin{array}{l}\text { Different forms of } \\
\text { cutaneous tuberculosis }\end{array}$ & Histopathological features & $\begin{array}{c}\text { Observation of } \\
\text { AFB }\end{array}$ \\
\hline \multicolumn{3}{|c|}{ Well-formed granulomas with absence of caseous necrosis } \\
\hline Lupus vulgaris & $\begin{array}{l}\text { epidermis may be atrophic or } \\
\text { hypertrophic, featuring acanthosis, } \\
\text { papillomatosis and even } \\
\text { pseudo-epitheliomatous hyperplasia. } \\
\text { Presence of well-formed tuberculous } \\
\text { granulomas accompanied more often by } \\
\text { Langhans giant cells, or foreign body-like } \\
\text { granulomas in the reticular dermis. }\end{array}$ & infrequent \\
\hline Lichen scrofulosorum & $\begin{array}{l}\text { non-caseating, epithelioid cell } \\
\text { granulomas in upper dermis and around } \\
\text { dermal appendages }\end{array}$ & not seen \\
\hline \multicolumn{3}{|c|}{ Intermediate forms: granulomas with caseous necrosis } \\
\hline $\begin{array}{l}\text { Tuberculosis verrucosa } \\
\text { cutis }\end{array}$ & $\begin{array}{l}\text { marked pseudoepitheliomatous } \\
\text { hyperplasia of the epidermis with } \\
\text { hyperkeratosis and dense inflammatory } \\
\text { cell infiltrate consisting of neutrophils, } \\
\text { lymphocytes, and giant cells. The } \\
\text { presence of granulomatous infiltrates is a } \\
\text { cardinal sign }\end{array}$ & can be seen \\
\hline $\begin{array}{l}\text { Primary cutaneous } \\
\text { tuberculosis }\end{array}$ & $\begin{array}{l}\text { it varies according to the time of } \\
\text { inoculation; in recent lesions there is the } \\
\text { presence of necrotizing neutrophilic } \\
\text { infiltrate with numerous AFB. At a later } \\
\text { stage there is organization of granulomas }\end{array}$ & $\begin{array}{l}\text { decreased } \\
\text { number }\end{array}$ \\
\hline Acute miliary tuberculosis & $\begin{array}{l}\text { skin consists of areas of an inflammatory } \\
\text { infiltrate composed of lymphocytes, } \\
\text { plasma cells, and neutrophils with focal } \\
\text { superficial dermal areas of necrosis and } \\
\text { abscess formation without true caseating } \\
\text { granuloma. The presence of acid-fast } \\
\text { bacilli with vascular thrombi is } \\
\text { characteristic of these lesions }\end{array}$ & can be seen \\
\hline Tuberculosis orificialis & $\begin{array}{l}\text { there are tuberculoid granulomas, around } \\
\text { a median, central, and superficial ulcer } \\
\text { accompanied by caseous necrosis in the } \\
\text { deep dermis }\end{array}$ & $\begin{array}{l}\text { not usually } \\
\text { found }\end{array}$ \\
\hline Papulonecrotic tuberculid & $\begin{array}{l}\text { lesions showed psoriasiform epidermal } \\
\text { hyperplasia, and epithelioid granulomas } \\
\text { with lymphocytes and Langhans giant } \\
\text { cells with variable amounts of necrosis } \\
\text { seen in the upper and mid dermis with a } \\
\text { perifollicular distribution }\end{array}$ & $\begin{array}{l}\text { not usually } \\
\text { found }\end{array}$ \\
\hline \multicolumn{3}{|c|}{ Poorly formed granulomas with intense caseous necrosis } \\
\hline Scrofuloderma & $\begin{array}{l}\text { Massive central necrosis with abscess } \\
\text { formation and in many cases, } \\
\text { suppuration, traces of granulomas can be } \\
\text { observed at periphery of the lesions }\end{array}$ & may be found \\
\hline $\begin{array}{l}\text { Metastatic abscesses and } \\
\text { gumma }\end{array}$ & $\begin{array}{l}\text { Central ulceration with abundant caseous } \\
\text { necrosis, surrounded by a rim of giant } \\
\text { cells and macrophages can be observed }\end{array}$ & $\begin{array}{l}\text { frequently } \\
\text { detected }\end{array}$ \\
\hline
\end{tabular}


TABLE 4: Sensitivity and specificity of PCR in the diagnosis of cutaneous tuberculosis (literature review).

\begin{tabular}{|c|c|c|c|}
\hline References and date & No. of samples & Sensitivity (\%) & Specificity (\%) \\
\hline (Lee et al. 2016) & 574 & 51.1 & 86.3 \\
\hline & & 100 & $\begin{array}{c}100 \text { (multi-bacillary } \\
\text { form) }\end{array}$ \\
\hline (Tan et al. 2001) & 105 & $\begin{array}{l}\text { Overall } 73 \text { (positivity of } 55 \% \text { in cases of } \\
\text { tuberculosis verrucosa and } 60 \% \text { in } \\
\text { cases of lupus vulgaris; positivity of } \\
54 \% \text { for cases of erythema induratum) }\end{array}$ & $\begin{array}{c}\text { not calculated } \\
\text { (pauci-bacillary form) }\end{array}$ \\
\hline (Chawla et al. 2009) & 104 & 74.1 & 96.1 \\
\hline (Agarwal et al. 2017) & 70 & 24.5 & not calculated \\
\hline (Salian et al. 1998) & $\begin{array}{l}60 \text { (formalin } \\
\text { fixed paraffin } \\
\text { embedded) }\end{array}$ & 73.6 & 100 \\
\hline (Ogusku et al. 2003) & 37 & 43.7 & 90.4 \\
\hline (Negi et al. 2005) & 37 & 95.2 & 100 \\
\hline (Abdalla et al. 2009) & 34 & 88 & 83 \\
\hline (Hsiao et al. 2003) & 34 & 56 & not calculated \\
\hline (Lall et al. 2017) & 31 & 25.8 & not calculated \\
\hline (Khosravi et al. 2006) & $\begin{array}{l}30 \text { (formaline } \\
\text { fixed) }\end{array}$ & 75 & not calculated \\
\hline (Ramam et al. 2013) & 28 & 25 & 73.7 \\
\hline (Khine et al. 2017) & 25 & 52 & not calculated \\
\hline (Quiros et al. 1996) & 20 & 85 & not calculated \\
\hline
\end{tabular}

clinical applicability testing of these genotyping techniques was also accessed in the patients with cutaneous tuberculosis in China by Ziang et al., 2017, with augmented sensitivity and specificity [57].

10.2.7. RFLP (Restriction Fragment Length Polymorphism). The gold standard in genotyping, IS6110-based restriction fragment length polymorphism (RFLP), has been for more than an epoch; however, it is laborious and costly and requires a large amount of chromosomal DNA [56].

10.2.8. Spoligotyping. Spoligotyping-commonly used to differentiate Mycobacterium tuberculosis complex strain-is based on polymorphisms of the chromosomal direct repeat (DR) locus, which contains a variable number of short DRs interspersed with nonrepetitive spacers $[56,57]$.

10.2.9. Mycobacterial Interspersed Repetitive Unit-Variable Number Tandem Repeat (MIRU-VNTR). Lately, the International consortium has proposed MIRU-VNTR as a standardized genotyping scheme, with 15- and 24-locus sets proven to have ample discriminatory power for tracing transmission and investigating the phylogenetics of tuberculosis [57].

\section{Conclusions}

In a limelight, almost all of the investigative methods confer lesser sensitivity and specificities for cutaneous tuberculosis, considering atypical erythema nodosum, nonspecific appearance, insufficiently elucidative radio-imaging approaches, histopathology features, and even microbial culture techniques too. The genotyping techniques, nevertheless, could be an assistant to cope with this diagnostic challenge, paradoxically beyond reach to the third world like ours, due to expensive running cost and wanting equipped laboratory setup. In this perspective, the clinicians must resort to every possible test, so that supporting positive rudiments would be ancillary in the early and precise diagnosis of cutaneous tuberculosis.
Abbreviations
AFB: $\quad$ Acid-fast bacilli
MDR-TB: $\quad$ Multiple drug resistant tuberculosis
MIRU-VNTR: Mycobacterial Interspersed Repetitive
Mtb: $\quad$ Mycobacterium tuberculosis
NTP: National Tuberculosis control Programme
PCR: $\quad$ Polymerase chain reaction
TST: Tuberculin skin test
XDR-TB: $\quad$ Extensively drug resistant tuberculosis.

\section{Conflicts of Interest}

The authors declare that they have no conflicts of interest.

\section{Acknowledgments}

The authors would like to thank Professor Dr. Jeevan Bahadur Sherchand (Department of Microbiology, Institute of Medicine) and Professor Dr. Dwarika Prasad Shrestha 
(Department of Dermatology and Venerology, Institute of Medicine).

\section{References}

[1] L. van Zyl, J. du Plessis, and J. Viljoen, "Cutaneous tuberculosis overview and current treatment regimens," Tuberculosis, vol. 95, pp. 629-638, 2018.

[2] J. B. dos Santos, A. R. Figueiredo, C. E. Ferraz, M. H. de Oliveira, P. G. da Silva, and V. L. S. de Medeiros, "Cutaneous tuberculosis: Epidemiologic, etiopathogenic and clinical aspects - Part I," Anais Brasileiros De Dermatologia Journal, vol. 89, no. 2, pp. 219-228, 2014.

[3] N. Saxe, "Mycobacterial skin infections," Journal of Cutaneous Pathology, vol. 12(3-4), pp. 300-312, 1985.

[4] World Health Organization, lobal Tuberculosis Report 2017: Leave no one behind - Unite to end TB, 2017.

[5] Anonymous, "World TB day," Nature Reviews Microbiology, vol. 2, no. 5, Article ID 39490114, p. 360, 2004, http://ovidsp.ovid .com/ovidweb.cgi.

[6] Global Tuberculosis Report, WHO Library Cataloguing-inPublication, 2016.

[7] B. Dwari, A. Ghosh, R. Paudel, and P. Kishore, "A clinicoepidemiological study of 50 cases of cutaneous tuberculosis in a tertiary care teaching hospital in Pokhara, Nepal," Indian Journal of Dermatology, vol. 55, no. 3, pp. 233-237, 2010.

[8] M. Mathur and S. N. Pandey, "Clinicohistological profile of cutaneous tuberculosis in Central Nepal," Kathmandu University Medical Journal, vol. 12, no. 48, pp. 238-241, 2014.

[9] Y. Pang, H. Dong, Y. Tan, Y. Deng, X. Cai, and H. Jing, "Rapid diagnosis of MDR and XDR tuberculosis with the MeltPro TB assay in China," Nature Publishing Group, pp. 1-8, 2016.

[10] X. Tao, Y. Guan, and Y. Mo, "Multidrug resistant Mycobacterium tuberculosis in cutaneous tuberculosis in China," Annals of Nigerian Medicine, vol. 7, no. 2, p. 71, 2013.

[11] V. Ramesh, M. K. Sen, and D. P. Sethuraman G, "Cutaneous tuberculosis due to multidrug-resistant tubercle bacilli and difficulties in clinical diagnosis," Indian Journal of Dermatology, vol. 8, no. 4, pp. 380-384, 2015.

[12] S. Ho, "Cutaneous Tuberculosis: Clinical Features, Diagnosis and Management," Hongkong Dermatology Venereol Bull, vol.11, pp. 130-138, 2003.

[13] C. Aruna, A. L. Senthil, K. Sridevi, K. Swapna, and D. V. S. B. Ramamurthy, "A clinicoepidemiological study of cutaneous tuberculosis in a tertiary care teaching hospital in Andhra Pradesh, India," International Journal of Research in Dermatology, vol. 3, no. 1, pp. 88-93, 2017.

[14] I. Smith, "Mycobacterium tuberculosis pathogenesis and molecular determinants of virulence," Clinical Microbiology Reviews, vol. 16, no. 3, pp. 463-496, 2003.

[15] Z. Yang, D. Yang, Y. Kong et al., "Clinical relevance of Mycobacterium tuberculosis plcD gene mutations," American Journal of Respiratory and Critical Care Medicine, vol. 171, no. 12, pp. 14361442, 2005.

[16] M. F. R. G. Dias, F. Bernardes Filho, M. V. Quaresma, L. V. do Nascimento, J. A. D. C. Nery, and D. R. Azulay, "Update on cutaneous tuberculosis," Anais Brasileiros de Dermatologia, vol. 89, no. 6, pp. 925-938, 2014.

[17] F. Abebe and G. Bjune, "The protective role of antibody responses during Mycobacterium tuberculosis infection," Clinical \& Experimental Immunology, vol. 157, no. 2, pp. 235-243, 2009.
[18] F. G. Bravo and E. Gotuzzo, "Cutaneous tuberculosis," Clinics in Dermatology, vol. 25, no. 2, pp. 173-180, 2007.

[19] S. Ramarao, J. N. Greene, B. C. Casanas, M. L. Carrington, J. Rice, and J. Kass, "Cutaneous Manifestation of Tuberculosis," Infectious Diseases in Clinical Practice, vol. 20, no. 6, pp. 376383,2012

[20] M. Concha R, F. Fch S, R. Rabagliati B et al., "Tuberculosis cutánea: reporte de dos casos y revisión de la literatura," Revista chilena de infectología, vol. 28, no. 3, pp. 262-268, 2011.

[21] V. Ramesh, "Sporotrichoid cutaneous tuberculosis," Clinical and Experimental Dermatology, vol. 32, no. 6, pp. 680-682, 2007.

[22] N. N. Andrade and T. S. Mhatre, "Orofacial Tuberculosis-A 16-Year Experience With 46 Cases," Journal of Oral and Maxillofacial Surgery, vol. 70, no. 1, pp. e12-e22, 2012.

[23] R. R. Macgregor, "Cutaneous tuberculosis," Clinics in Dermatology, vol. 13, no. 3, pp. 245-255, 1995.

[24] A. H. Solis, N. E. González, F. Cazarez et al., "Skin biopsy: a pillar in the identification of cutaneous Mycobacterium tuberculosis infection," The Journal of Infection in Developing Countries, vol. 6 , no. $08,2012$.

[25] A. Motta, C. Feliciani, A. De Benedetto, F. Morelli, and A. Tulli, "Lupus vulgaris developing at the site of misdiagnosed scrofuloderma," Journal of the European Academy of Dermatology and Venereology, vol. 17, no. 3, pp. 313-315, 2003.

[26] A. Frankel, C. Penrose, and J. Emer, "Cutaneous tuberculosis: a practical case report and review for the dermatologist," The Journal of Clinical and Aesthetic Dermatology, vol. 2, no. 10, Article ID 20725570, pp. 19-27, 2009.

[27] M. Almagro, J. Del Pozo, J. Rodríguez-Lozano, J. García Silva, M. T. Yebra-Pimentel, and E. Fonseca, "Metastatic tuberculous abscesses in an immunocompetent patient," Clinical and Experimental Dermatology, vol. 30, no. 3, pp. 247-249, 2005.

[28] P. del Giudice, E. Bernard, C. Perrin et al., "Unusual Cutaneous Manifestations of Miliary Tuberculosis," Clinical Infectious Diseases, vol. 30, no. 1, pp. 201-204, 2000.

[29] A. Singal and S. Sonthalia, "Cutaneous tuberculosis in children: The Indian perspective," Indian Journal of Dermatology, Venereology and Leprology, vol. 76, no. 5, pp. 494-503, 2010.

[30] G. Jacobsen, N. J. Samolitis, and R. M. Harris, "Lichenoid Eruption in a Patient With AIDS-Quiz Case," JAMA Dermatology, vol. 142, no. 3, 2006

[31] I. Hadj, M. Meziane, O. Mikou, K. Inani, T. Harmouch, and F. Z. Mernissi, "Tuberculous gummas with sporotrichoid pattern in a 57-year-old female: A case report and review of the literature," International Journal of Mycobacteriology, vol. 3, no. 1, pp. 6670, 2014.

[32] C. Chandrashekar, G. V. Anikethana, B. E. Kalinga, and I. S. Hasabi, "Cutaneous tuberculosis: a differential for chronic nonhealing ulcer," Journal of Evolution of Medical and Dental Sciences, vol. 3, no. 53, pp. 12366-12370, 2014.

[33] J. B. dos Santos, C. E. Ferraz, P. G. da Silva, A. R. Figueiredo, M. H. de Oliveira, and V. L. S. de Medeiros, "Cutaneous tuberculosis: Diagnosis, histopathology and treatment - Part II," Anais Brasileiros de Dermatologia, vol. 89, no. 4, pp. 545-555, 2014.

[34] "Targeted tuberculin testing and treatment of latent tuberculosis infection," American Journal of Respiratory and Critical Care Medicine, vol. 161, 3, pp. S221-S247, 2000.

[35] S. Nayak and B. Acharjya, "Mantoux test and its interpretation," Indian Dermatology Online Journal (IDOJ), vol. 3, no. 1, p. 2, 2012. 
[36] M. Ramam, A. Malhotra, T. Tejasvi et al., "How useful is the Mantoux test in the diagnosis of doubtful cases of cutaneous tuberculosis?" International Journal of Dermatology, vol. 50, no. 11, pp. 1379-1382, 2011.

[37] J. Barbagallo, P. Tager, R. Ingleton, R. J. Hirsch, and J. M. Weinberg, "Cutaneous tuberculosis: diagnosis and treatment," American Journal of Clinical Dermatology, vol. 3, no. 5, pp. 319$328,2002$.

[38] J. Almaguer-Chávez, J. Ocampo-Candiani, and A. Rendón, "Current panorama in the diagnosis of cutaneous tuberculosis," Actas Dermo-Sifiliográficas, vol. 100, no. 7, pp. 562-570, 2009.

[39] C. Aliaǧaoğlu, M. Atasoy, A. I. Güleç et al., "Tuberculosis verrucosa cutis," European Journal of General Medicine, vol. 6, no. 4, pp. 268-273, 2009.

[40] F. Peters, M. Batinica, G. Plum, S. A. Eming, and M. Fabri, "Bug or no bug: challenges in diagnosing cutaneous mycobacterial infections," Journal of the German Society of Dermatology, vol. 14, no. 12, pp. 1227-1236, 2016.

[41] T. Frevel, K. L. Schäfer, M. Tötsch, W. Böcker, and B. DockhornDworniczak, "PCR based detection of mycobacteria in paraffin wax embedded material routinely processed for morphological examination," Journal of Clinical Pathology: Molecular Pathology, vol. 52, no. 5, pp. 283-288, 1999.

[42] M. M. Ogusku, A. Sadahiro, M. H. Hirata, R. D. C. Hirata, C. Zaitz, and J. I. Salem, "PCR in the diagnosis of cutaneous tuberculosis," Brazilian Journal of Microbiology, vol. 34, no. 2, pp. 165170, 2003.

[43] C. Suthar, T. Rana, U. B. Singh et al., "MRNA and DNA PCR tests in cutaneous tuberculosis," Indian Journal of Dermatology, Venereology and Leprology, vol. 79, no. 1, pp. 65-69, 2013.

[44] C. M. Z. Abdalla, Z. N. P. De Oliveira, M. N. Sotto, K. R. M. Leite, F. C. Canavez, and C. M. De Carvalho, "Polymerase chain reaction compared to other laboratory findings and to clinical evaluation in the diagnosis of cutaneous tuberculosis and atypical mycobacteria skin infection," International Journal of Dermatology, vol. 48, no. 1, pp. 27-35, 2009.

[45] S. H. Tan, H. H. Tan, and G. C. Sun YJ, "Clinical utility of polymerase chain reaction in the detection of Mycobacterium tuberculosis in different types of cutaneous tuberculosis and tuberculids," ANNALS Academy of Medicine, vol. 30, pp. 3-10, 2001.

[46] P.-F. Hsiao, C.-Y. Tzen, H.-C. Chen, and H.-Y. Su, "Polymerase chain reaction based detection of Mycobacterium tuberculosis in tissues showing granulomatous inflammation without demonstrable acid-fast bacilli," International Journal of Dermatology, vol. 42, no. 4, pp. 281-286, 2003.

[47] P. Agarwal, E. N. Singh, U. S. Agarwal, R. Meena, S. Purohit, and S. Kumar, "The role of DNA polymerase chain reaction, culture and histopathology in the diagnosis of cutaneous tuberculosis," International Journal of Dermatology, vol. 56, no. 11, pp. 1119$1124,2017$.

[48] E. Veringa, B. Van Harsselaar, and P. Hermans, "Polymerase chain reaction to detect Mycobacterium tuberculosis in a clinical microbiology laboratory," Journal of Microbiological Methods, vol. 16, no. 2, pp. 139-147, 1992.

[49] Y. J. Lee, S. Kim, Y. Kang et al., "Does polymerase chain reaction of tissue specimens aid in the diagnosis of tuberculosis?" Journal of Pathology and Translational Medicine, vol. 50, no. 6, pp. 451458, 2016.

[50] E. Quiros, M. C. Maroto, A. Bettinardi, I. Gonzalez, and G. Piedrola, "Diagnosis of cutaneous tuberculosis in biopsy speci- mens by PCR and southern blotting," Journal of Clinical Pathology, vol. 49, no. 11, pp. 889-891, 1996.

[51] K. K. Zaw, A. G. WWA, and PWE, "Cutaneous TB: Different Clinical Types and Comparing the Values of its Diagnostic Tests," Myanmar Health Sciences Research Journal, vol. 29, no. 2, 2017.

[52] S. S. Negi, S. F. Basir, S. Gupta, S. T. Pasha, S. Khare, and S. Lal, "Comparative study of PCR, smear examination and culture for diagnosis of cutaneous tuberculosis," Journal of Communicable Diseases, vol. 37, no. 2, pp. 83-92, 2005.

[53] A. D. Khosravi and M. Omidian, "Application of polymerase chain reaction technique for laboratory diagnosis of cutaneous tuberculosis," Pakistan Journal of Medical Sciences, vol. 22, no. 3, pp. 291-294, 2006.

[54] H. Lall, N. Singh, M. Chaudhary, and I. Kaur, "Comparison of conventional and molecular methods in diagnosis of extrapulmonary (cutaneous) tuberculosis in a tertiary care hospital in Delhi," International Journal of Medical Science and Public Health, vol. 6, no. 1, p. 102, 2017.

[55] K. Chawla, S. Gupta, C. Mukhopadhyay, P. S. Rao, and S. S. Bhat, "PCR for M. tuberculosis in tissue samples," The Journal of Infection in Developing Countries, vol. 3, no. 02, 2009.

[56] Genotyping CA group on T. Guide to the Application of Genotyping to Tuberculosis Prevention and Control. 2004.

[57] H. Jiang, Y. Jin, V. Vissa et al., "Molecular characteristics of mycobacterium tuberculosis strains isolated from cutaneous tuberculosis patients in China," Acta Dermato-Venereologica, vol. 97, no. 4, pp. 472-477, 2017. 


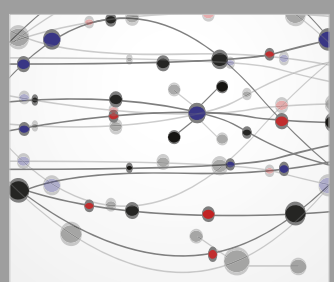

The Scientific World Journal
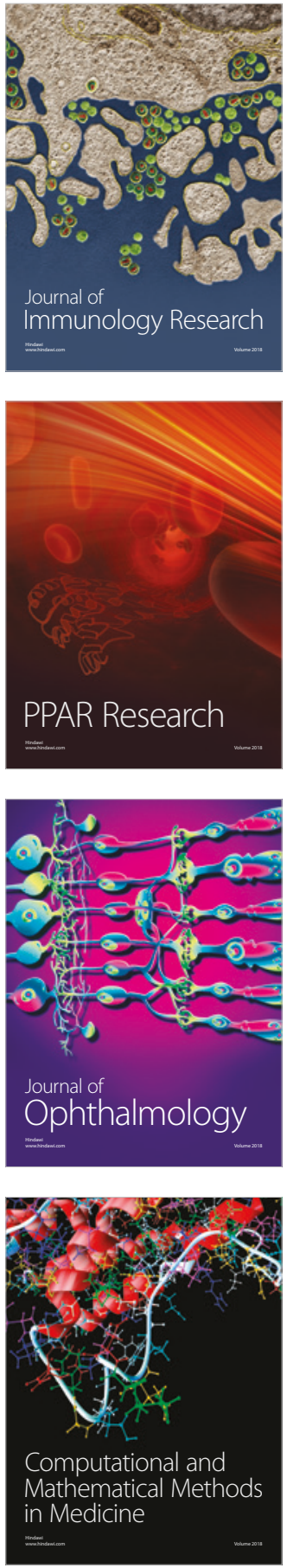

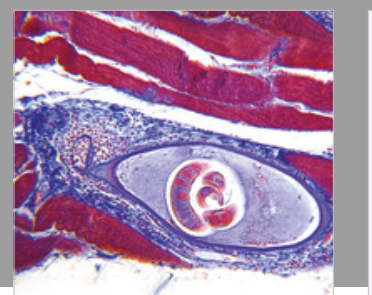

Gastroenterology Research and Practice

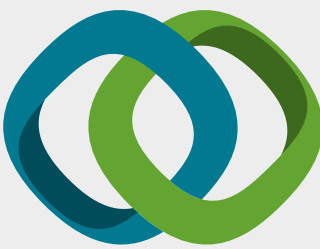

\section{Hindawi}

Submit your manuscripts at

www.hindawi.com
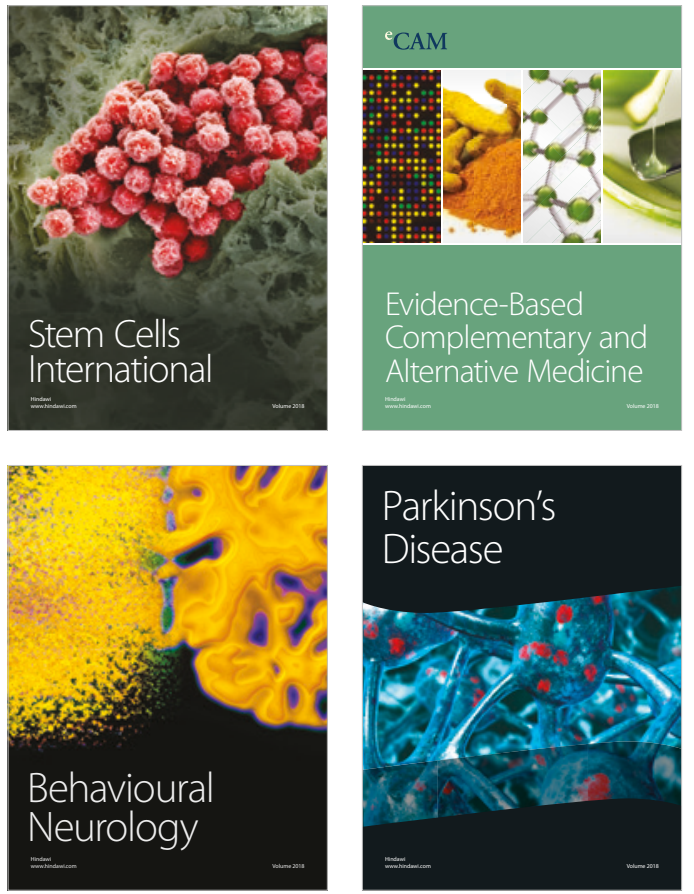

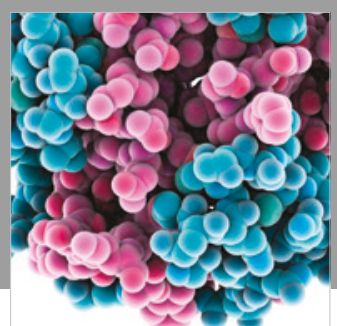

ournal of

Diabetes Research

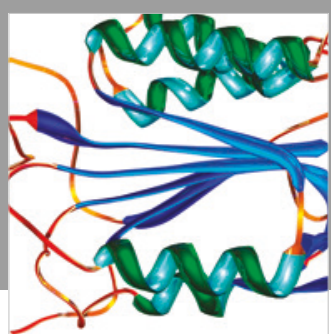

Disease Markers
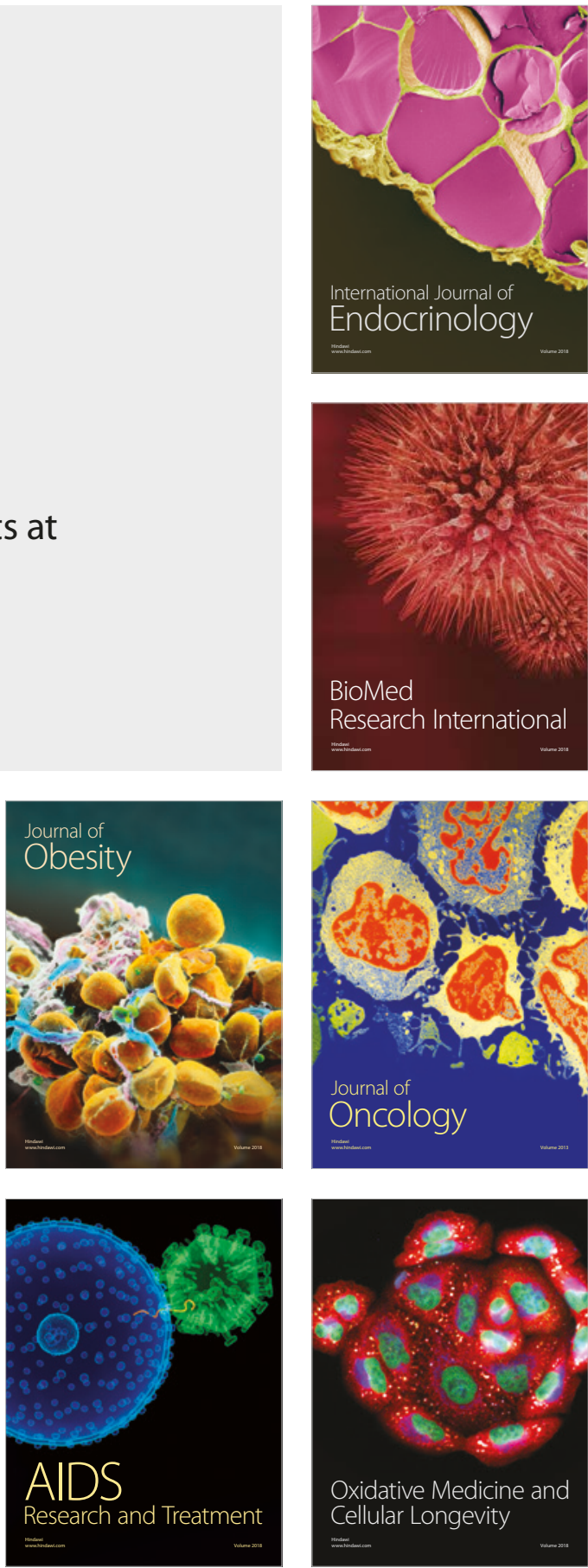